\title{
Investigation of Link between Customer Satisfaction and Customers Price Sensitivity
}

\author{
Mansoureh Aligholi \\ Department of Business Management, Faculty of Management, \\ Central Tehran Branch, Islamic Azad University, Tehran, Iran \\ Shokoofeh Heydari \\ Department of Business Management, Qazvin Branch, Islamic Azad University, Qazvin, Iran. \\ ${ }^{*}$ Corresponding Author: Email: Heydarishokoofeh@gmail.com \\ Hossein Shahbazi \\ MSC of Planning and Geography- tutor Payam Noor University, SarablehBarnch, Iran
}

\section{Doi:10.5901/mjss.2014.v5n20p3098}

\section{Abstract}

The present research to investigation of the link between customer Satisfaction and customer's price sensitivity of the wear store's. customer Satisfaction is divided to economic satisfaction and social.. The main objective of the research is investigation of the link between customer Satisfaction and customer's price sensitivity. To gather information two ways are used slibrary studies for explaining the existed theoretic literature and a questionnaire for measuring the research variable's. The population includes the customers who has been shopped the wear store's in kermanshah. Multiple-stage cluster sampling method used. A Total of 450 Questionnaires was distributed that 385 responses of them were usable for data analysis. Data were analyzed using the structural equation modeling (SEM) technique. Research finding's says that economic satisfaction and social satisfaction has inverse relationship with price sensitivity. Both. Customer satisfaction has inverse relationship with price sensitivity.

Keywords: economic satisfaction, price sensitivity, social satisfaction

\section{Introduction}

In any organization, whether a production or a service organization, customers' satisfaction is the main factor in conservation and survival of the organization. If the organization is not successful in attracting customers' satisfaction and loyalty, it will not guarantee its long-term growth (Rahnama et al, 2012). Many studies have focused on customer's satisfaction during the past years because customer's satisfaction is considered as a key factor in success in business environment (Bosque and Martin, 2008). Ravald and Gronroos (1996) believe that satisfaction is an after-consumption evaluation which is formed based on comparison of expected value before consumption and perceived value after consumption, via product or service purchase (Yoo et al, 2010). Price sensitivity means how individuals perceive price variations or differences in products and services and how respond to it. Price sensitivity is usually concerned with price variations (Wakefield and Inman, 2003). Customers evaluate their satisfaction with a product or service via comparing value received from it and the money paid for it. If customer satisfaction is high, he or she tends to pay more money. In other words, his or her sensitivity to price will decrease and vice versa (Low et al, 2013).

\subsection{Statement of the problem}

Over the past few years, consumption in retailing industry has been largely affected by changes in lifestyles and industrial structures. Tohmatsu believes that retailing industry is the main index for economic development of countries. Some studies have investigated the relationship between customer's satisfaction and price sensitivity in markets but in many developing countries, relationship between price and satisfaction is common especially in retailing systems (Low et al, 2013). In many previous studies, customer's satisfaction has been investigated in general form but the present research deals with both economic and social satisfaction. Further, the present research aims to develop and test a more 
comprehensive model for investigation of relationship between CS (economic satisfaction and social satisfaction) and customer's price sensitivity. Considering the above discussion and novelty of the research and also applicable and useful results of the research for managers of clothing retailing system, it seems necessary to conduct this research.

\subsection{Necessity and importance of the research}

Many studies have been conducted on Customer satisfaction (CS). It has been described as a sentimental evaluation. Attraction of customer satisfaction has a direct relationship with customer maintenance, market share increase and profitability. Therefore, it has received a lot of attention by corporate managers. This is because satisfied customers will probably talk about their good experiences with other people (AlizadehMoshkani, Karimi, 2012). CS is important because it increases customer life cycle. Moreover, concentration on customer satisfaction will minimize negative messages by dissatisfied customers. According to previous studies, a dissatisfied customer talks about his or her problem with at least 9 people and $13 \%$ of such dissatisfied customers talk about their dissatisfaction with more than 20 people (VazirZanjani et al, 2010). Although relationship between CS and price sensitivity has been investigated by marketing researchers, there is no comprehensive model to include both economic satisfaction and social satisfaction. Customers' loyalty is therefore an important factor in business success. It must be noted that loyal customers have many benefits for an organization. These include improvement of profitability, reduction in marketing costs, increase in total sales, low level of sensitivity to price and so on (Rahnama et al, 2012). Therefore, the present study fills the gap of development of a comprehensive model which includes both economic and social satisfaction in order to help understand relationship between CS and price sensitivity.

\section{Theoretical Research Framework}

\subsection{Customer satisfaction (CS)}

Customers' loyalty is of strategic importance for any organization. Increase in customers' loyalty is a controversial matter for managers and academics (Haghighi et al, 2012). Blanchard and Galovi believe that customer satisfaction forms as a result of customer's perception in a value relationship or transaction and price equals ratio of conducted services quality to customer's costs. There is one ambiguous aspect in satisfaction literature and that is "whether satisfaction has a sentimental structure or not? Or is it a cognitive structure based on a sentimental dimension?". In fact, satisfaction is the result of a cognitive and an emotional section of evaluation of a consumption process both of which are essential in modeling consumer behavior. Furthermore, Oliver believes that in addition to diverse cognitive judgments, feeling plays role in creating role and it is necessary for understanding customers' consumption process. Therefore, some dimensions of satisfaction show its cognitive aspect and some others show its sentimental nature (Hallowell, 1996). It must be noted that CS does not depend on the type of organizational activity or on organizational situation but it depends on organizational ability to satisfy expected quality (Kavousi, Saghayee, 2005). Satisfaction is a positive response and is resulted from an expectable experience. Before a new purchase, customers compare their expectations with previous experience(Vazifehdoost, Rahnama\&Mousavian, 2014).

\subsection{Economic satisfaction}

It refers to functional aspects of and economic consequences of a purchase which includes product attractiveness and quality, satisfaction with cost and so on (Low et al, 2013). Economic satisfaction or satisfaction with product is a popular subject of study. In general, satisfaction with product refers to a customer's satisfaction with product quality and its usefulness. According to equity theory, people analyze the equality of transactions they have with others. They analyze their own output-to-input ratios with those of their partners in a transaction. If they feel they have higher shares, they feel inequality. According to equity theory, both sides must be treated justly. Therefore, satisfaction is reached when outputto-input ratios of both sides are approximately equal. When a buyer believes that his or her output/input ratio is worse than that of the seller, he or she experiences inequality and this results in dissatisfaction.From a consumer's viewpoint, inputs, information, attempt, money or time make a transaction possible. Outputs are benefits received from the transaction. For a seller, Outputs can be in the form of products or services received by product performance and feelings achieved by the transaction (Moven and Minor, 2009). 


\subsection{Social satisfaction}

Social satisfaction has been defined as evaluation of psychological aspects from personal communications and transactions (Sahadev, 2006). It includes positive and friendly service attitudes, service processes, respect and politeness of salespeople and so on (Low et al, 2013). Customer satisfaction has two dimensions in marketing literature; transactional dimension (economic), and relational dimension (social). Transactional dimension of CS refers to a customer's evaluation of purchases he or she makes. Relational dimension of CS refers to a customer's general feeling and evaluation of treatments and behaviors (Beerli et al, 2004). Relational satisfaction refers to cognitive and effective evaluation based upon personal experience all over a relationship. Therefore, relational satisfaction can be resulted from evaluation of a purchaser's working relationship with a supplier. A customer's evaluation of relational satisfaction with a supplier is vital to development of future business transactions and positive transactions result in long-term relationship (Lages et al, 2008).

\subsection{Price sensitivity}

Price sensitivity refers to change in a customer's demand as a result of price reduction or increase. In economics, it is called price elasticity. A company which serves customers with low price sensitivity has more competitive advantage in its services and products and this leads to higher organizational profitability. Many factors may affect price sensitivity; for instance:exposure to advertisement, purchase background and knowledge about a product (Low et al, 2013). Price sensitivity means how individuals see price differences and variations in products and services and how respond to them. Price sensitivitystudies are usually focused on response to price changes. In other words, price sensitivity means: consumers' response to price change, format and appearance (Wakefield and Inman, 2003).

\subsection{Conceptual model}

In this section, a conceptual model has been provided for investigation of relationship between CS and customers' price sensitivity. The model is based on Low et al (2013) research model. In this model, CS, economic satisfaction and social satisfaction are independent variables and price sensitivity is considered as a dependent variable.

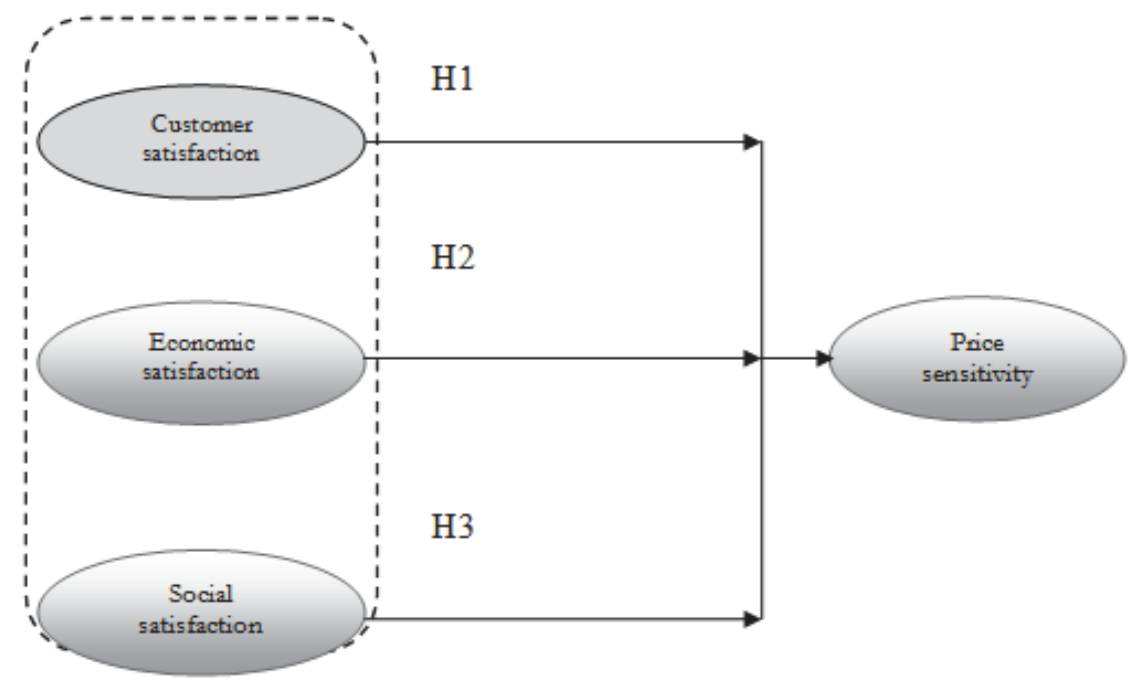

Figure 1: research conceptual model

Source: Low et al, 2013 


\section{Research Hypotheses}

1. CS has a negative relationship with price sensitivity.

2. Economic satisfaction has a negative relationship with price sensitivity.

3. Social satisfaction has a negative relationship with price sensitivity.

\section{Methodology}

The present research is an applied study (in terms of target) because it makes use of previous findings to help mangers use them in decision-making. The present research is a descriptive study because variables are not manipulated. In order to collect data, library study was used. The research is a survey because data collection instrument (questionnaire) was distributed among respondents. Further, the research is a correlation study because it deals with relationships among variables. furthermore, the research is a correlation study because it investigates relationships among variables.

a. topic domain of the resent research is consumer behavior and it concentrates on areas like CS, economic satisfaction, social satisfaction and price sensitivity.

b. place domain of the research is clothing stores situated in Kermanshah City, Iran.

c. data were collected in August 2013 from respondents.

Statistical population of the present research included all customers of clothing stores in Kermanshah City. Cochran's statistical model was used for determining sample size because population size was large and the number of population members is ambiguous. Sample size was estimated to be equal to 385 people. Multistage cluster sampling was used for picking sample members. First, customers of clothing stores were selected as population. Then, we selected a final small cluster after several steps. To this end, first we selected three districts out of the 6 districts of the city. Then, the three districts were divided in two areas and some sub-areas were picked. Then, clothing stores situated in the sub-areas were selected randomly. In the end, customers of the clothing stores were randomly selected as sample members and respondents. The questionnaire used in this survey is made up of two sections: demographic information of respondents and main questions. The demographic section contains questions about age, gender, education and marital status of the respondents. This section helps collect data needed for descriptive analysis. The main section of the questionnaire contains 13 questions for measuring 4 variables; 8 questions for measuring CS, 4 questions for evaluating economic satisfaction, 4 questions for evaluating social satisfaction and 5 questions for measuring price sensitivity. The questionnaire is based upon Low et al (2013) standard questionnaire. This questionnaire has been translated twice and the questions have been compared to each otherand the best equivalents have been selected for words. The questions are based on 5-point Likert scale (completely agree, agree, no comment, disagree and completely disagree). Furthermore, Chronbach's alpha was used for measuring reliability of the questions. Total Cronbach's coefficient was equal to 0.803 .

\section{Data Analysis}

Parametric inferential statistics were used for testing the hypothesis. Moreover, structural equations modeling method (in LISREL software) and Pearson correlation coefficient (in SPSS) were used for analysis. Every complete structural equations model is a combination of path analysis and factor analysis. Usually, in studies which are aimed at testing a special model of relationships, the most appropriate method is structural equations modeling method. Pearson correlation coefficient indicates the intensity and direction of relationship between the two variables. a positive coefficient means a positive relationship and a negative coefficient is a negative relationship.

\section{Research Findings for Research Hypotheses}

In this section we deal with hypotheses test. In order to test the hypotheses, we used structural equations modeling (using LISREL software) and Pearson correlation coefficient (using SPSS software). As it can be seen in figure 1, research conceptual model in significant state was used for testing the second and third hypotheses. In this state, if ------ is smaller than -1.96 of greater than $1.96, \mathrm{H} 0$ is rejected and $\mathrm{H} 1$ is verified and Pearson correlation coefficient indicates the direction of the two variables. a positive coefficient means a positive relationship and a negative coefficient refers to a negative relationship. Of course, Kolmogrov-Smearnov test was conducted to test normality of data. 


\subsection{Data normality test}

Kolmogrov-Smearnov test was used for testing normality of data. in this test, $\mathrm{H} 0$ indicates normal distribution of data:

$$
\begin{aligned}
& H_{0}: \rho=0 \\
& H_{1}: \rho \neq 0
\end{aligned}
$$

In this test, if significance level is smaller than $0.05, \mathrm{H} 0$ is rejected and if significance level is greater than $0.05, \mathrm{H} 1$ is supported. Results of factors normality test have been summarized in table 1.

Table 1. Normality of variables test

\begin{tabular}{|l|c|c|c|}
\hline & Kolmogrov-Smearnov Z statistic & significance level & result \\
\hline price sensitivity & 1.21 & 0.11 & normal \\
\hline economic satisfaction & 0.87 & 0.43 & normal \\
\hline social satisfaction & 1.04 & 0.16 & normal \\
\hline customer satisfaction & 0.95 & 0.29 & normal \\
\hline
\end{tabular}

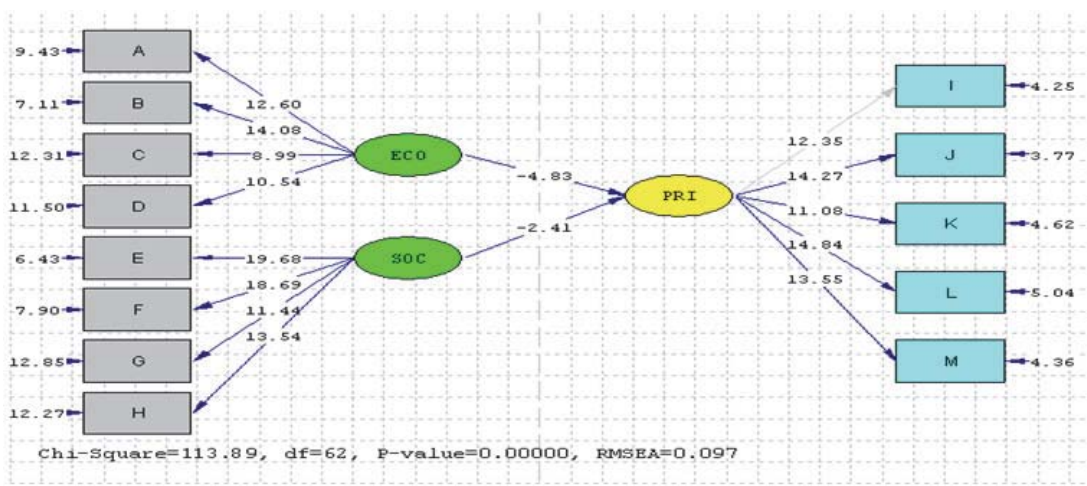

Figure 2. Research structural model in significance state

\subsection{Model fit indices}

In hypotheses tests using structural equations modeling, software output indicates good model fit for test. Ratio of Kaisquared to df is one of the best indices for investigation of goodness of fit. Allowable limit for this index is 3 . In the present research, this value was smaller than 3 and therefore acceptable. RMSEA is another index the allowable limit of which is smaller than 0.1 . this value is smaller than 0.1 in the structural equations model. it is better to consider several indices instead of one single index for determining fitness of model. as it can be seen in table 2, other fit indices are acceptable. Therefore, it can be said that the present conceptual model is of good fit.

Table 2: Model fit indices

\begin{tabular}{c|ccccc}
\hline result & AGFI & GFI & Df & RMSEA & Kai-sqaured \\
\hline good fitness & 0.97 & 0.98 & 62 & 0.097 & 113.89 \\
\hline
\end{tabular}

First, second and third hypotheses analysis:

Table 3: correlation coefficient between price sensitivity and satisfaction

\begin{tabular}{|c|l|c|c|c|}
\hline \multicolumn{2}{|c|}{} & economic satisfaction & social satisfaction & Customer's satisfaction \\
\hline \multirow{3}{*}{ price sensitivity } & Correlation coefficient & -0.475 & -0.274 & -0.569 \\
\cline { 2 - 5 } & significance level & 0.000 & 0.000 & 0.000 \\
\cline { 2 - 5 } & number & 385 & 385 & 385 \\
\hline
\end{tabular}


In this section, Pearson correlation coefficient was used for testing the first, second and third hypotheses using SPSS software. Moreover, LISREL software was used to test the second and third hypotheses.

It must be mentioned that in statistical software, statistic value is calculated for each test and then, significance level ( $p$ value) is presented considering the statistic distribution. This is compared with first type error level ( 0.05 in here). If $(-p)$ value or the very significance level is greater than or equal to $0.05, \mathrm{H} 0$ is verified and if it is smaller than $0.05, \mathrm{H} 0$ is rejected and $\mathrm{H} 1$ is verified.

Considering the fact that the significance level of correlation coefficient of rice sensitivity and satisfaction dimensions is smaller than 0.05 , there is a negative and significant correlation between price sensitivity and CS, social satisfaction and economic satisfaction. Therefore, the first, second and third hypotheses are supported.

\subsection{Second hypothesis test:}

Software output indicates that the fitted structural model is good for the second hypothesis. Furthermore, figure 1 shows that the coefficients are significant only when their significance test value is greater than 1.96 and smaller than -1.96 . Considering T-value (-4.83) which is smaller than -1.96 , it can be concluded that there is a negative relationship between economic satisfaction and price sensitivity for Kermanshah clothing stores customers.

\subsection{Third hypothesis test:}

Software output indicates that the fitted structural model is good for the third hypothesis. Furthermore, figure 1 shows that the coefficients are significant only when their significance test value is greater than 1.96 and smaller than -1.96 . considering T-value (-2.41) which is smaller than -1.96 , it can be concluded that there is a negative relationship between social satisfaction and price sensitivity for Kermanshah clothing stores customers.

\section{Conclusion and Discussion}

Results of the research verified the presence of negative relationship between CS, economic satisfaction, social satisfaction and price sensitivity.

According to the results, there is a negative relationship between clothing stores customers' satisfaction and price sensitivity. In other words, we expect that as consumer's satisfaction increases, customers' tend to pay higher prices and therefore price sensitivity decreases. If product quality and attraction increases, customer's economic satisfaction will also increase and therefore price sensitivity is decreased. Clothing stores salespeople and owners can have warm and friendly relationships with customers, deal with their problems and respond to complaints so that the customers' social satisfaction is increased and their price sensitivity is decreased. Results of this research in the second hypothesis conform to the results of Low et al (2013). The results verified that customers' price sensitivity is decreased if customers are provided with high-quality services and products.

There are some managerial hints concluded from the results. Clothing producers and managers can provide good products and therefore decrease their price sensitivity. Therefore, they can increase their profitability. A second hint is that when previous customers become aware of prices increases, companies with competitive advantages can provide products which produce high economic satisfaction in customers and therefore create loyal customers. A third hint is that considering the negative relationship between social satisfaction and customers' price sensitivity, social satisfaction factors like positive service attitude of customers towards store, provision of customers' necessary information and politeness of salespeople towards customers should be strengthened.

\section{References}

AlizadehMeshkani, Fattaneh and Karimi, Mehdi. A comparison of loyalty of customers of Refah and Farhangiyan Chain Stores (case study: Qom City sample stores). Google.

Beerli, A., Martin, J.D., Quintana, A. (2004). A Model of Customer Loyalty in the Retail Banking Market. European Journal of Marketing, $38(1 / 2)$.

Bosque, Ignacio Rodriguezdel and MartínHe'ctor San (2008). Tourist satisfaction A Cognitive-Affective Model. Published by Elsevier, , Vol. 35, No. 2.

Foongyee, Wong and Xian, Tan Hwee(2012). Price Sensitivity-Consumer Satisfaction Relationship towards Electrical Appliances, World Journal of Social Sciences. Vol. 2. No. 6. September 2012 Issue. 
Geyskens,Inge and Steenkamp,Jan- Bendict E. M(2000). Economic and social satisfaction: measure- ment and relevance to marketing channel. Journal of Retailing, Volume 76 (1).

Haghighi, Mohammad; Dorosti, Ali; Rahnama, Afshin; Hoseinpour, Ali;(2012) 'Evaluation of factors affecting customer loyalty in the restaurant industry' African Journal of Business Management Vol. 6(14), pp. 5039-5046.

Hallowell, Roger( 1996). The relationships of Sustomer Satisfaction, Customer loyalty, and profitability: an empirical study. International Journal of Service Industry Management, Vol. 7 No. 4, Harvard Business School, Boston, MA, USA @ MCB University Pres.

Heidarzadeh, Kambiz and Irani, Neda (2011), investigation of the role of benefit-based value and hedonistic value in consumers' satisfaction with clothing purchase in Iran; quarterly of development and change management.

Huber, F., Herrmann, A., Wricke, M., (2001). Customer satisfaction as an antecedent of price acceptance: results of an empirical study. Journal of Product\& Brand Management . VOL. 10 NO. 3 2001,MCB UNIVERSITY PRESS.

Kavousi, Seyyed Mohammad Reza and Saghayee, Abbas (2005). Methods of customer satisfaction measurement, Sabzan Publications, second printing.

Lages, Luis Filipe and Lancastre, Andrew and Lages, Carmen(2008) «The B2B-RELPERF scale and scorecard: Bringing relationship marketing theory into business-to-business practice»,Industrial Marketing Management, Vol. 37, №. 6.

Low, wen-Shinn and Lee, Jeng-Da and Cheng, Soo- May (2013). The link between customer satisfaction and price sensitivity: An investigation of retailing industry in Taiwan. Journal of Retailing an Consumer Services, 20.

Moven, John and Minor, Mishel, KambizHeidarzadeh (translator); (2009), consumer behavior, Ghazvin Islamic Azad University Publications, first printing.

Munnukka, Juha (2005). Dynamics of price sensitivity among mobile service customers. Journal of Product \& Brand Management. Vol14, No1, in Finland.

Rahnama, Afshin; Alaei, Abbas; Shafaee, Javad; Ariana, Ali;(2012) "Evaluation of Relationship Marketing Dimension Effect on Degree of Customer's Loyalty of Insurance Industry in Iran" Journal of Basic and Applied Scientific Research, 2(2)1842-1848

Rahnama, Afshin; Alaei, Abbas; Shafaee, Javad; Hamdam, Hadi;(2012) "Evaluating the Impact of Banking Services Quality on Customer Loyalty in Mellat Bank Ardebil Province"Journal of Basic and Applied Scientific Research, 2(3)2498-2506.

Sahadev, Sunil (2006). Economic Satisfaction and Relationship Commitment in Channels: The Moderating Role of Environmental Uncertainty, Collaborative Communication and Coordination Strategy. Indian Institute of Management Kozhikode, IIMK Campus PO, Kozhikode, Kerala, India.

Vazifehdoost, Hossein; Rahnama, Afshin; Mousavian, SeyedJavad; (2014), "Evaluation of the Impact of Brand Purchase Involvement, Satisfaction, Experience and Brand Trust on Loyalty to Brand" Mediterranean Journal of Social Sciences MCSER Publishing, Rome-Italy; Vol 5 No 20, pp: 3054-3063.

Wakefield, Kirk L and Inman, Jeffrey Inman (2003). Situational price sensitivity: the role of con- sumption occasion, social context and income. Journal of Retailing. 79.

Xie, Hui and Bao, Jigang and Morais, Duarte B (2006). Exploring Gender Differences in information Search Among Domestic Vistora to Yellow Mountain and Guilin, PRC.. Proceedings of the 2006 Northeastern Recreation Research Symposium.

Yoo, W.S., Lee, Y., Park, J. (2010). The Role of Interativity in E-Tailing: Creating Value and Increasing Satisfaction. Journal of Retailing and Consumer Services, 17, 89-96.

Zeng, Fueand yang, Zhilin and li, Yongqiang and Fam,Kim-SHyan.,(2011)."Small business industrial buyers' price sensitivity: Do service quality dimensions matter in business markets? ". Industrial Marketing Management. 40. 